Saudi Journal of Oral and Dental Research

Abbreviated Key Title: Saudi J Oral Dent Res ISSN 2518-1300 (Print) |ISSN 2518-1297 (Online) Scholars Middle East Publishers, Dubai, United Arab Emirates Journal homepage: https://saudijournals.com/sjodr

\title{
Diagnostic accuracy of PA Radiography, Complementary Metal-Oxide Semiconductor Sensor (CMOS), Photo Stimulable Phosphor Plate Receptor (PSP) and Cone Beam CT in the Detection of Internal Root Resorption; An In Vitro study"
}

\author{
Dr. Josey Mathew ${ }^{1 *}$, Dr. Gibi Syriac ${ }^{2}$, Dr. A Devadathan ${ }^{3}$, Dr. Manuja Nair ${ }^{4}$, Dr. Jose Jacob ${ }^{5}$, Dr. Rahul J ${ }^{6}$ \\ ${ }^{1}$ Professor, Dept of Conservative Dentistry \& Endodontics, Annoor Dental College, Muvattupuzha, Kerala, India \\ ${ }^{2}$ Assistant Professor, Department of Pediatric and Preventive Dentistry, Government Dental College, Kottayam, Kerala, India \\ ${ }^{3}$ HOD and Professor, Dept of Conservative Dentistry \& Endodontics, Pushpagiri College of Dental Sciences, Tiruvalla, Kerala, India \\ ${ }^{4}$ Reader, Dept of Conservative Dentistry \& Endodontics, Pushpagiri College of Dental Sciences, Tiruvalla, Kerala, India \\ ${ }^{5}$ Reader, Dept of Conservative Dentistry \& Endodontics, Pushpagiri College of Dental Sciences, Tiruvalla, Kerala, India \\ ${ }^{6}$ Reader, Dept of Conservative Dentistry \& Endodontics, Pushpagiri College of Dental Sciences, Tiruvalla, Kerala, India
}

\begin{abstract}
DOI: $10.36348 /$ sjodr.2020.v05i04.002
| Received: 04.04.2020 | Accepted: 11.04.2020 | Published: 13.04.2020
\end{abstract}

*Corresponding author: Dr. Josey Mathew

\section{Abstract}

Background: Radiologic diagnostic methods for internal resorption include conventional periapical radiography (PA radiography), Complementary metal Oxide Semiconductor imaging (CMOS), Photostimulable phosphor (PSP) imaging and Cone beam Computed Tomography (CBCT). This study aims to examine the sensitivity and specificity of CBCT, PSP, CCD, and PA Radiography for early diagnosis of internal resorption. Material \& methods: 72 single-rooted premolars were divided into three intervention groups and a control group. The teeth were split mesiodistally into two parts. Cavities of $0.3 \mathrm{~mm}$ depth were created on the buccal half of the root in middle one third in Group A. In Group B cavities of $0.4 \mathrm{~mm}$, Group C cavities of $0.6 \mathrm{~mm}$ and in control Group D no cavities were created. Finally, the teeth fragments were fused using glue, fixed in sockets of one human dry mandible and were examined with the four different procedures. Results: The sensitivity of the four imaging procedures for diagnosis of internal root resorption of $0.3 \mathrm{~mm}$ was $100 \%, 60 \%, 73 \%$, and $53 \%$ respectively. However, the sensitivity of all four procedures for diagnosis of internal root resorption with $0.4 \mathrm{~mm}$ and $0.6 \mathrm{~mm}$ in depth was the same and equal to $100 \%$. The specificity of the four procedures for diagnosis of internal root resorption of any depth was100\%, 83\%, 100\%, and 75\% respectively. Conclusion: CBCT provides the most accurate information on the depth and location of root resorption followed by the CMOS and PSP respectively. Conventional intraoral periapical radiography was the least accurate procedure.

Keywords: Internal resorption, CBCT, PSP, PA X-Ray, CMOS.

Copyright @ 2020: This is an open-access article distributed under the terms of the Creative Commons Attribution license which permits unrestricted use, distribution, and reproduction in any medium for non-commercial use (NonCommercial, or CC-BY-NC) provided the original author and source are credited.

\section{INTRODUCTION}

Physiologic or a pathologic process resulting in a loss of dentin, cementum, and/or bone is known as resorption [1]. It is classified as internal or external root resorption depending on its location.

Progressive defect of intra-radicular dentin and dentinal tubules along the middle and apical thirds of root canal walls caused by bacterial invasion and chronic inflammation of dental pulp tissue results in internal resorption [2]. Internal resorption is associated with irreversible pulpitis wherein dentin and cementum are dissolved by chelation. The possible causating factors are trauma and inflammation. Internal root resorption is asymptomatic but the untreated internal resorption can progress weakening the teeth causing fracture of the tooth [3]. Clinical decisions depend on early and accurate diagnosis resulting in more predictable outcomes. This makes early diagnosis and prompt treatment very important to improve the prognosis of teeth with resorption [4].

Radiologic methods used for diagnosis of internal resorption include conventional intraoral periapical radiography (PA radiography), Complementary metal Oxide Semiconductor imaging (CMOS) and photostimulable phosphor (PSP) imaging plate. Intraoral radiography can be done in two waysanalog and digital. The conventional films are exposed to radiation and fixed in the processing solution in analog method. Digital intraoral technique can be done 
directly and indirectly. In the direct method images are visible immediately after radiography on the monitor (e.g. CMOS). In the indirect method, the sensor exposed to radiation is placed in a scanner. The scanner is then exposed to the laser beam and the image appears on the monitor (e.g. PSP). In addition to these, conebeam computed tomography (CBCT) is used extensively for early detection of dental disease including root resorption. CBCT provides threedimensional images of the maxillofacial structures using Cone beam $[5,6]$.

Conventional intraoral radiography offers twodimensional image of three dimensional anatomies [7]. CBCT provides a three-dimensional view eliminating superimposition of structures that is inherent in conventional imaging and also offer axial, sagittal, and coronal views [8]. Very few studies have been conducted to investigate the accuracy of conventional and digital intraoral imaging techniques with CBCT for early detection of internal root resorption. This study aims to examine the sensitivity and specificity of four imaging procedures including CBCT, PSP, CCD, and PA Radiography for early diagnosis of internal root resorption.

\section{MATERIALS \& METHODS}

Seventy two single-rooted premolars without root resorption were selected and saved in normal saline The teeth were divided into three intervention groups and a control group of 18 teeth each.

\section{Preparing and simulating root resorption}

A diamond disk was used to split the teeth mesiodistally into Two parts. (Fig 1) Then, cavities of $0.3 \mathrm{~mm}$ depth were created on the buccal half of the root in middle one third by round bur in first intervention group (Group A)using Bur No 45(Mani Inc., Japan). In Group B cavities of $0.4 \mathrm{~mm}$ in depth were prepared in the same location using round bur No 46(Mani Inc., Japan).In Group C cavities of $0.6 \mathrm{~mm}$ was prepared using round bur No 31(Mani Inc., Japan). The 18 teeth of the control Group D were split to be as similar as the teeth of intervention groups but no cavities were created in them. Finally, the teeth fragments were fused using glue and were fixed in sockets of one human dry Mandible. (Fig 2) Apical half of the teeth were cut off for ease of placement in the mandible. To simulate facial soft tissue, all surfaces of the mandibles were covered by approximately $2 \mathrm{~mm}$ thick pink wax. Then, the teeth were examined with the four different imaging procedures. Fig 4 to Fig 7 shows PA Xray, CMOS, PSP and CBCT images showing internal resorption respectively.

\section{Imaging techniques}

Each specimen was subjected to PA Radiography, CMOS imaging, PSP imaging and CBCT imaging.
Group I - PA Radiography using Kodak E speed film and Best-x-DC, Xray Machine (NewLife Radiology Italy)at $70 \mathrm{KV}, 180 \mathrm{~mA}$ for $0.540 \mathrm{sec}$ Group II - CMOS using Kodak 5100 RVG and Best-XDC, Xray Machine (NewLife Radiology Italy) at 70KV, $220 \mathrm{~mA}$ for $0.180 \mathrm{sec}$

Group III - PSP using Vistascan mini plus imaging system (Durr Dental)

Group IV - CBCT using Planmeca CBCT at 90Kv, 8 $\mathrm{mA}$ and romexis viewer software

\section{Finally groups can be summarised as}

- Group I A; 0.3mm defect with P.A Radiography

- Group I B; 0.4mm defect with P.A Radiography

- Group I C; 0.6mm defect with P.A Radiography

- Group I D; 0 mm defect with P.A Radiography

- Group II A; 0.3mm defect with CMOS radiography

- Group II B; $0.4 \mathrm{~mm}$ defect with CMOS radiography

- Group II C; 0.6mm defect with CMOS radiography

- Group II D; 0 mm defect with CMOS radiography

- Group III A; 0.3mm defect with PSP radiography

- Group III B; $0.4 \mathrm{~mm}$ defect with PSP radiography

- Group III C; 0.6mm defect with PSP radiography

- Group III D; 0 mm defect with PSP radiography

- Group IV A; $0.3 \mathrm{~mm}$ defect with CBCT

- Group IV B; 0.4mm defect with CBCT

- Group IV C; $0.6 \mathrm{~mm}$ defect with CBCT

- Group IV D; 0 mm defect with CBCT

\section{Interpretation of the images}

The images were interpreted by two endodontists independently. They were blind to the presence or absence of root resorption. The observers' judgment on the images was categorized as either positive or negative.

\section{STATISTICAL ANALYSIS}

To estimate the sensitivity and specificity of the imaging methods, we divided the images as positive or negative based on the observers' judgments and reported as a percentage using results of CBCT imaging as the gold standard. All statistical analyses were performed at $95 \%$ significance level.

\section{RESULTS}

The sensitivity and specificity of CBCT, PSP, CMOS, and PA for diagnosis internal root resorption by resorption depth are shown in Table 1 and Table 2 respectively. The sensitivity of the four imaging procedures for diagnosis of internal root resorption of $0.3 \mathrm{~mm}$ in depth was $100 \%, 60 \%, 73 \%$ and $53 \%$ respectively. However, the sensitivity of all four procedures for diagnosis of internal root resorption with $0.4 \mathrm{~mm}$ and $0.6 \mathrm{~mm}$ in depth was the same and equal to $100 \%$. The specificity of the four procedures for diagnosis of internal root resorption of any depth was $100 \%, 83 \%, 100 \%$ and $75 \%$ respectively.

Table-1: Sensitivity of imaging techniques 
Josey Mathew et al; Saudi J Oral Dent Res, April, 2020; 5(4): 214-218

\begin{tabular}{|l|l|l|l|l|}
\hline Depth of cavity & PA X Ray & CMOS & PSP & CBCT \\
\hline $0.3 \mathrm{~mm}$ & 53 & 73 & 60 & 100 \\
\hline $0.4 \mathrm{~mm}$ & 100 & 100 & 100 & 100 \\
\hline $0.6 \mathrm{~mm}$ & 100 & 100 & 100 & 100 \\
\hline Average & 84 & 91 & 87 & 100 \\
\hline
\end{tabular}

Table-2: Specificity of imaging techniques

\begin{tabular}{|l|l|l|l|l|}
\hline Depth of cavity & PA X Ray & CMOS & PSP & CBCT \\
\hline $0.3 \mathrm{~mm}$ & 75 & 100 & 83 & 100 \\
\hline $0.4 \mathrm{~mm}$ & 75 & 100 & 83 & 100 \\
\hline $0.6 \mathrm{~mm}$ & 75 & 100 & 83 & 100 \\
\hline Average & 75 & 100 & 83 & 100 \\
\hline
\end{tabular}

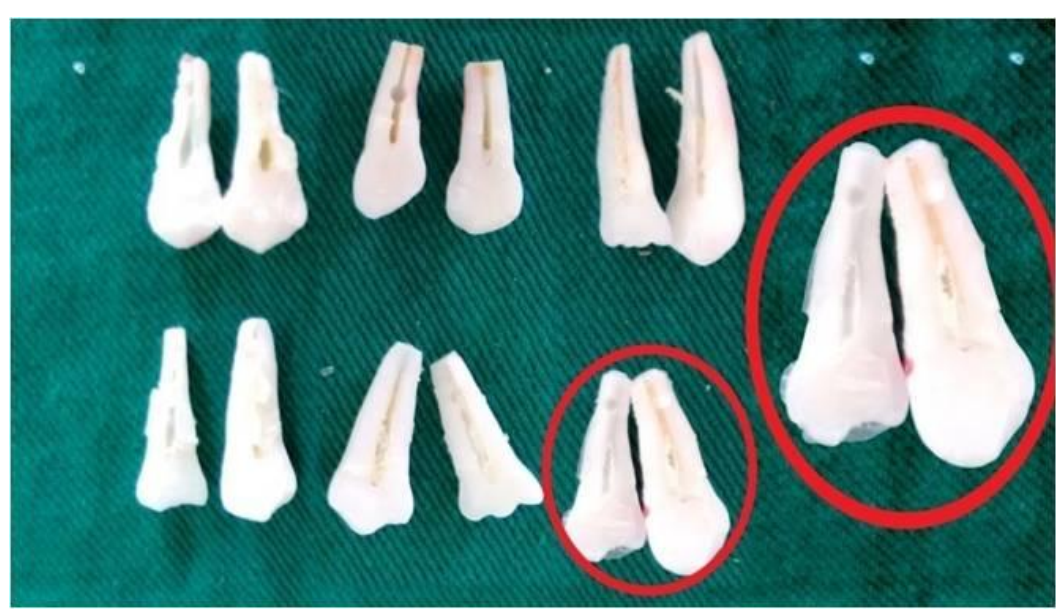

Fig-1: Teeth split mesiodistally
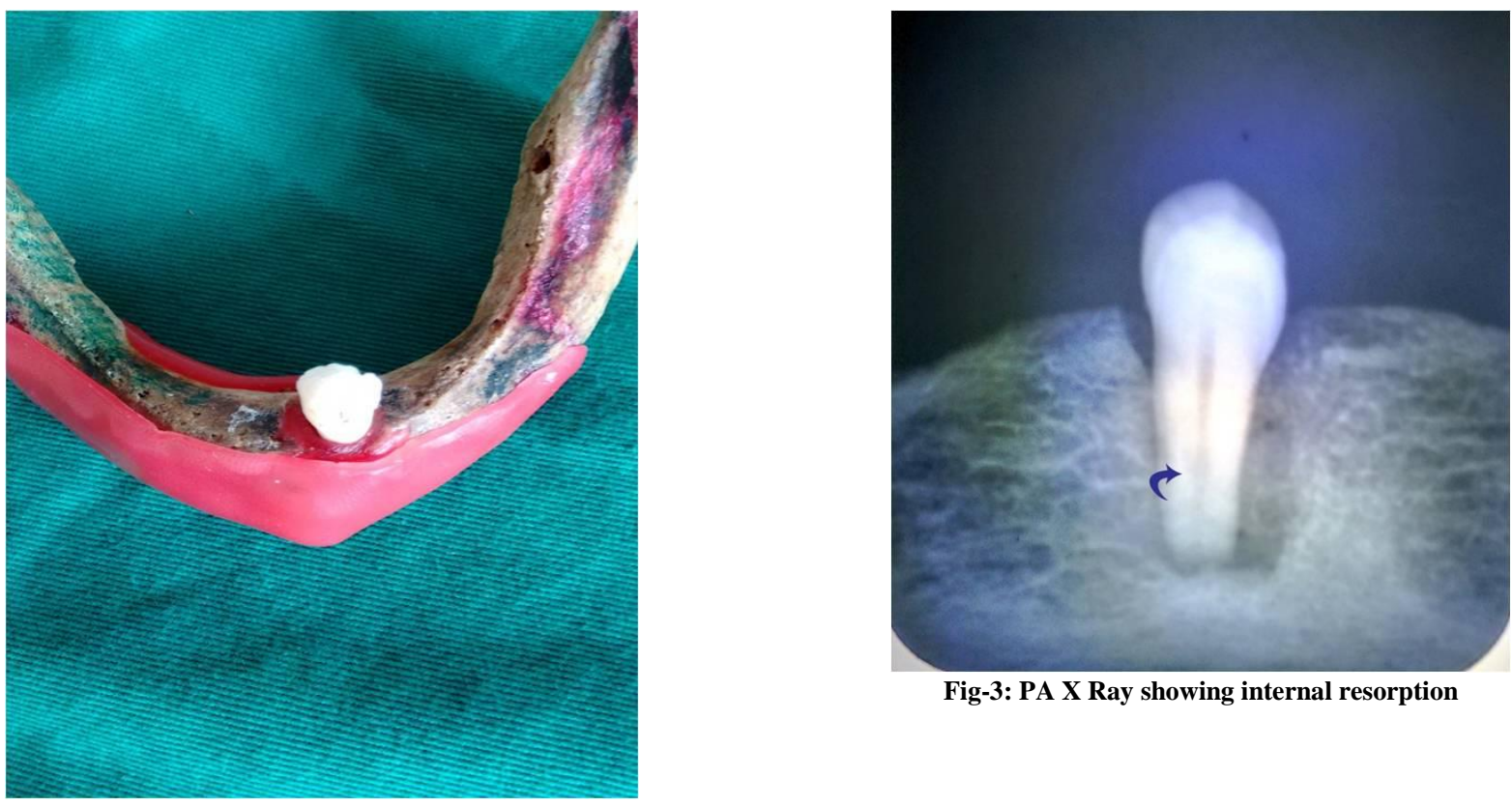

Fig-3: PA X Ray showing internal resorption

Fig-2: Tooth fixed in Mandible for imaging 


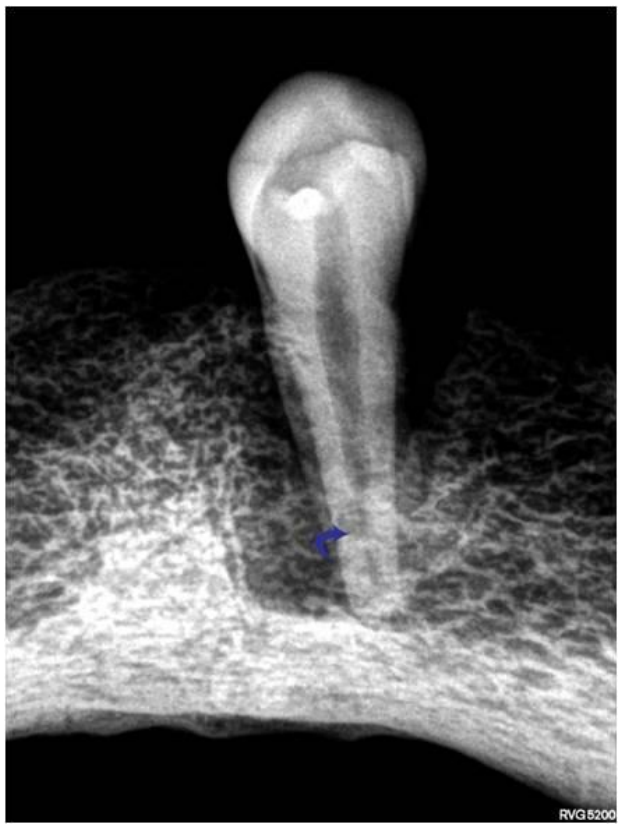

Fig-4: CMOS showing internal resorption

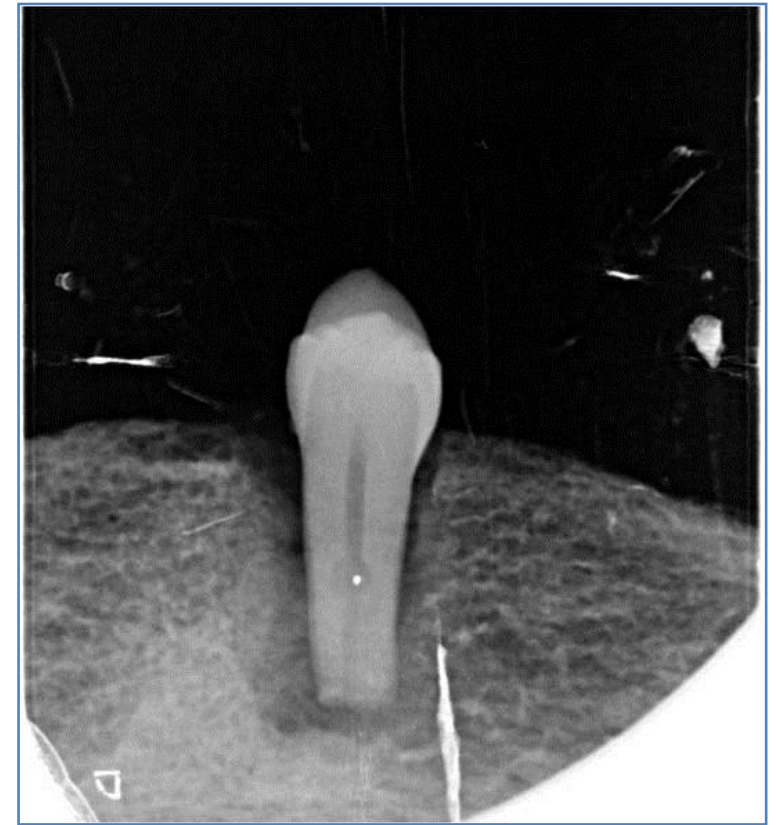

Fig-5: PSP showing internal resorption

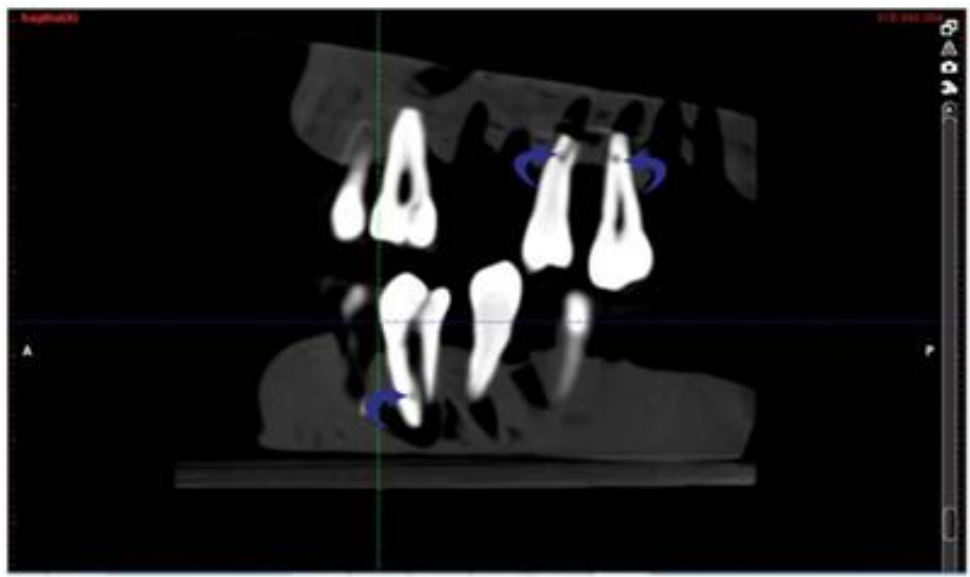

Fig-6: CBCT showing internal resorption

\section{DISCUSSION}

Diagnostic information offered by imaging procedures can influence clinical decisions. Accurate data provide clinically relevant information and can lead to better judgment. Early diagnosis of internal root resorption is critical for appropriate treatment [4].

This study shows that CBCT offers the most accurate and reliable information about internal root resorption compared to other procedures. The average sensitivity of CBCT, PSP, CMOS, and PA for diagnosis of internal root resorption $0.3 \mathrm{~mm}$ in depth was $100 \%$, $60 \%, 73 \%$, and $53 \%$ respectively. Average sensitivity of CBCT, PSP, CMOS, and PA for all lesion depths was $100 \%, 87 \%, 91 \%, 84 \%$ respectively. These results indicate that for diagnosing internal root resorption in the primary stages CBCT is better than conventional intraoral imaging techniques. This is due to the adjustment of the contrast and density of digital images as well as use of different software options such as noise reduction, magnification, enhancement etc [9].
Among digital intraoral imaging systems, CMOS has higher sensitivity compared to PSP. This shows that digital imaging systems are effective in diagnosing small internal root resorption. The results obtained in this study are in accordance with the results obtained in earlier studies [10].The study by Murphy et al to determine the accuracy and reliability of recording forensic information from cone beam computed tomography (CBCT) scans of the jaws when compared to conventional panoramic radiographs proved nearperfect repeatability and reproducibility for CBCT with 96.6\% sensitivity and $98.4 \%$ specificity[11]. Ultra and high resolution $\mathrm{CBCT}$ has been proven to be effective in detecting similuated internal resorption defects [12].Shokri etal has stated that the most accurate information on the depth and location of root resorption is provided by CBCT followed by the PSP and CCD. Accordingly, conventional intraoral radiography was the least accurate procedure [13]. 
Although CBCT imaging system has higher accuracy than other systems, higher cost has limited its application for identifying the internal root resorption especially in the early stages. Therefore, CMOS is suggested to be considered as the first choice in diagnosing internal root resorption in patients with trauma because it can detect $73 \%$ of the internal root resorption of $0.3 \mathrm{~mm}$ in depth. If the results of PSP are negative at this stage, patients can be periodically followed up. If resorption is progressing, root resorption may be detected on follow up. However, CBCT may be used for more precise diagnosis especially when other diagnosis such as fracture is suspected [14]. There is no significant difference between CBCT and PSP in diagnosing internal root resorption of more than $0.4 \mathrm{~mm}$ in depth. Indeed, the diagnostic ability of all imaging systems increases with resorption depth as in previous studies [15].

The most important limitation of this study was that we created internal root resorption artificially and used dry human mandible for replacement of the prepared teeth. Although we tried to simulate the natural condition, the inherent difference between in vitro and in vivo may result in bias. Another limitation of this study was that we simulated root resorption and measured the ability of the imaging techniques in detecting internal resorption in single rooted teeth only. The results may vary in multi root teeth, especially the molars.

\section{CONCLUSION}

The current study examined and compared the accuracy of four different radiographic procedures in diagnosing internal root resorption. Based on the findings, $\mathrm{CBCT}$ provides the most accurate information on the depth and location of root resorption followed by the CMOS and PSP respectively. Conventional intraoral periapical radiography was the least accurate procedure.

\section{REFERENCES}

1. American Association of Endodontists, "Glossary of endodontic terms," 2012, http://www.aae.org/glossary.

2. Patel S, Ricelcci D, Durak C, Tay F. Internal root resorption: a review. J Endod. 2010;36(7):1107-21.

3. Maria R, Mantry V, Koolwal S. Internal resorption: a review and case report. Endodontology. 2010:100-8.

4. Patel S, Dawood A, Wilson R, Horner R, Mannocci F. The detection and management of root resorption lesions using intraoral radiography and cone beam computed tomography - an in vivo investigation. Int Endod J. 2009;42(9):831-8.

5. Alaerban A, Jacobs R, Souza P, Willems G. Invitro comparison of 2 cone-beam computed tomography systems and panoramic imaging for detecting simulated canine impaction-induced external root resorption in maxillary lateral incisors. Am $\mathbf{J}$ Orthod Dentofacial Ortho. 2009;136(6):764.e1-11.

6. Eskandarloo A, Mirshekari A, Poorolajal J, Mohammadi Z, Shokri A. Comparison of conebeam computed tomography with intraoral photostimulable phosphor imaging plate for diagnosis of endodontic complications: a simulation study. Oral surgery, oral medicine, oral pathology and oral radiology. 2012 Dec 1;114(6):e54-61.

7. Özer SY. Diagnosis and treatment modalities of internal and external cervical root resorptions: review of the literature with case reports. Int Dent Res. 2011;1:32-7.

8. Yajima A, Otonari-Yamamoto $\mathrm{M}$, Sano $\mathrm{T}$, Hayakawa Y, Otonari T, Tanabe K. Cone-beam CT (CB Throne) applied to dentomaxillofacial region. Bull Tokyo Dent Coll. 2006;47:133-41.

9. Scarfe WC, Levin MD, Gane D, Farman AG. Use of cone beam computed tomography in endodontics. International journal of dentistry. 2009;2009.

10. de Paula-Silva FW, Wu MK, Leonardo MR, da Silva LA, Wesselink PR. Accuracy of periapical radiography and cone-beam computed tomography scans in diagnosing apical periodontitis using histopathological findings as a gold standard. Journal of endodontics. 2009 Jul 1;35(7):1009-12.

11. Murphy M, Drage N, Carabott R, Adams C. Accuracy and reliability of cone beam computed tomography of the jaws for comparative forensic identification: a preliminary study. J Forensic Sci. 2012;57(4).

12. Kamburoglo K, Kursun S. A comparison of the diagnostic accuracy of CBCT images of different voxel resolusions used to detect simulated small internal resorption cavitise. Int Endod J. 2010;43(9):798-807.

13. 13.Shokri A, Poorolajal J, FaramarzI F Comparison of the accuracy of cone-beam computed tomography, photostimulable phosphor imaging plate, charge coupled device, and conventional intraoral radiography in the diagnosis of internal root resorption: an in vitro study. Braz Dent Sci. 2014 Jan/Mar;17(1).

14. Kajan ZD, Taromsari M. Value of cone beam CT in detection of dental root fractures. Dentomaxillofacial Radiology. 2012 Jan;41(1):310.

15. Kamburoglo K, Barenbiom SF, Kaffe I. Comparison of conventional film with different digital and digitally filtered images in the detection of simulated internal resorption cavities - an ex vivo study in human cadaver jaws. Oral Surg Oral Med Oral Pathol Oral Radiol Endod. 2008;105(6):790-7. 